\title{
Rancang bangun prototipe mesin gravir laser berbasis mikrokontroler arduino
}

\author{
Nanang Ali Sutisna ${ }^{1}$, Harist Fauzi ${ }^{1}$ \\ ${ }^{1}$ Program Studi Teknik Mesin, Universitas President \\ Jababeka Education Park, Jl. Ki Hajar Dewantara, Mekarmukti,Cikarang Utara, Bekasi 17550 \\ Email korespondensi: nanang.ali@president.ac.id
}

\begin{abstract}
Abstrak
Penggunaan dan kebutuhan mesin gravir laser saat ini mengalami peningkatan diantaranya untuk kegiatan produksi dan praktikum di beberapa sekolah kejuruan dan universitas teknik di Indonesia. Namun harga mesin gravir laser yang dipasaran masih cukup tinggi. Oleh karena itu perlu adanya langkah mencari solusi untuk mengatasi hal tersebut diantaranya dengan merancang bangun mesin gravir laser yang dikhususkan untuk keperluan praktikum dengan harga terjangkau. Sistem kontrol pada mesin gravir laser dirancang menggunakan mikrokontroler CNC 2 axis berbasis kontroler ATmega328 Arduino Nano, dengan penggerak tiga buah motor stepper sebagai aktuator, untuk menggerakkan mesin terhadap sumbu $x, y$, z dan modul laser dengan daya 2.500 $m W$. Untuk mencegah kerusakan jika ada kesalahan pergerakan, mesin dilengkapi tombol emergency stop. Penggunaan sistem kontrol dengan mikrokontroler CNC 2 axis berbasis ATmega328 Arduino nano dipilih pada Mesin gravir laser karena termasuk open source dan lebih terjangkau. Diharapkan dengan diterapkannya mikrokontroler berbasis ATmega328 Arduino nano sebagai prototipe, kedepannya sistem kontrol dapat dikembangkan lebih lanjut agar sistem kontrol lebih stabil. Dari hasil pengujian mesin gravir laser dengan menggunakan parameter jarak laser, daya laser dan kecepatan gerak laser, didapat nilai parameter mesin gravir terbaik yang dijadikan sebagai standar parameter.
\end{abstract}

Kata kunci: gravir laser, ATmega328 arduino nano, mikrokontroler CNC 2 axis.

\begin{abstract}
Nowaday, the use and demand of laser engraving machines is increasing for production and practical activities in vocational schools and engineering faculty in Indonesia. However, the price of laser engraving machine in the market is still quite high. Therefore there is a need to find a solution to overcome this problem by designing a laser engraving machine that is devoted for practical purposes at affordable prices. The control system on the laser engraving machine is designed using an Arduino Nano-based 2-axis CNC controller, with three stepper motor drive actuators, to drive the machine on the $x, y$, zaxes and laser axis with $2500 \mathrm{~mW}$ of power. To prevent damage if there is a movement error, the machine is equipped with emergency stop button. The use of a control system with an Arduino nano-based 2-axis CNC microcontroller is selected on the Laser engraving machine because it is open source and more affordable. It is expected that by implementing Arduino nano ATmega328 microcontroller as a prototype, in the future the control system can be developed further so that the control system is more stable. From the results of laser engraving machine testing using laser distance parameters, laser power and laser speed motion, obtained the value of the best engraving machine parameters to be used as standard parameters.
\end{abstract}

Keywords: laser engraving, ATmega328 arduino nano, CNC 2 axis microcontroller.

\section{Pendahuluan}

Seiring dengan kemajuan ilmu pengetahuan dan teknologi, aplikasi laser telah banyak digunakan dalam berbagai bidang. Penerapan aplikasi laser processing dapat berupa laser engraving, laser marking dan laser cutting [1,2]. Aplikasi gravir laser pada material merupakan teknologi yang telah banyak digunakan dewasa ini khususnya dalam bidang proses manufaktur. Keunggulan teknik gravir dengan menggunakan laser dibanding dengan metode konvensional adalah ketepatan pengerjaan lebih baik, proses gravir lebih presisi, karena dikontrol secara otomasi menggunakan sistem Computer Numerical Control (CNC) [3]. Pada proses gravir dengan menggunakan laser diperlukan adanya parameter yang tepat pada sistem kontrol untuk menjalankan mesin laser agar dapat beroperasi dengan baik dan benar [4]. Berdasarkan hal tersebut, untuk mendapatkan kualitas yang baik perlu adanya kombinasi pada proses gravir laser, antara lain jenis laser, daya laser, kecepatan laser dan jarak fokus atau laser head dengan benda kerja [5,6]. Jenis laser menentukan material yang dapat di proses gravir metal dan non-metal, Daya pada laser berpengaruh pada kemampuan gravir terhadap material, kemudian jarak laser head pada mesin gravir laser berpengaruh terhadap titik fokus yang dihasilkan pada proses gravir [7]. Sedangkan kecepatan gerak laser berpengaruh pada kekasaran hasil gravir pada permukaan benda kerja [8]. Sehingga dengan 
menggunakan parameter yang tepat pada suatu jenis material, maka dapat mengurangi kerugian akibat cacat atau kerusakan yang akan timbul pada hasil proses gravir laser [9]. Kajian dengan pengujian kekasaran permukaan, menganalisa hasil gravir laser atau mengukur diameter dari laser yang ditembakkan ke material sangat diperlukan [10]. Dengan kajian ini diharapkan dapat menghasilkan prototype mesin gravir laser yang sederhana dengan harga terjangkau, serta mendapatkan standar parameter pengoperasian mesin yang terbaik [11,12]. Mesin ini terutama dirancang sebagai sarana praktikum di lingkungan kampus atau sekolah menengah kejuruan. Menguraikan secara jelas tentang latar belakang umum kajian; studi pustaka secara singkat tentang penelitian-penelitian terkait untuk memastikan kebaruan artikel ini (harus ada rujukan ke jurnal 10 tahun terakhir); gap analysis berupa pernyataan kesenjangan, kebaruan (novelty statement) atau beda unik pada kajian ini dibandingkan dengan penelitian terdahulu, permasalahan yang harus dijelaskan secara eksplisit serta hipotesis bila diperlukan, metode pendekatan penyelesaian masalah, kontribusi ilmiah atau tujuan dalam artikel ini.

\section{Metode}

Kajian ini dibatasi antara lain mencakup tentang: jenis laser yang digunakan adalah jenis laser dioda dengan daya $2500 \mathrm{~mW}$; material yang digunakan untuk proses gravir adalah non-metal, misalnya kertas, kain, kayu, plastik, mdf; parameter mesin gravir laser yang digunakan adalah daya laser, jarak laser head dan kecepatan pergerakan laser; program kontroler menggunakan library yang sudah ada; sistem kontrol menggunakan perangkat lunak Arduino IDE dan Laser GRBL [13]. Konstruksi mesin diasumsikan aman karena beban yang dipikul relatif ringan dan kecepatannya rendah [14]. Tahapan yang dilakukan pada kajian rancang bangun prototipe mesin gravir laser dengan mikrokontroler CNC 2 axis berbasis arduino nano adalah sebagaimana diperlihatkan dalam Gambar 1.

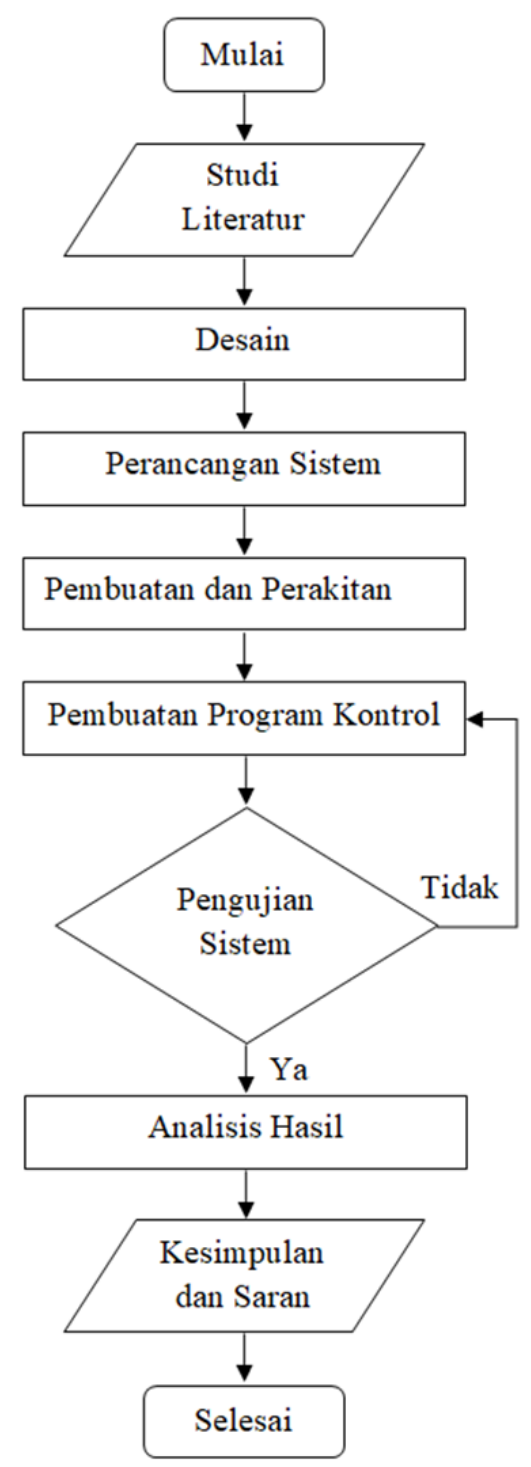

Gambar 1. Diagram alir perancangan.

Prototipe mesin gravir laser ini bekerja dengan mekanisme 2 sumbu dan sistem kontrol pada mesin gravir laser menggunakan mikrokontroler. Jenis sistem kontrol mesin gravir laser pada perancangan ini adalah loop terbuka. Dengan menggunakan mikrokontroler berbasis arduino nano, sebagai penerjemah G-Code menjadi pulsa yang dikirim ke driver aktuator dan driver laser (mosfet IRF5305S). Blok diagram kontrol sistem ditunjukkan pada Gambar 3. 


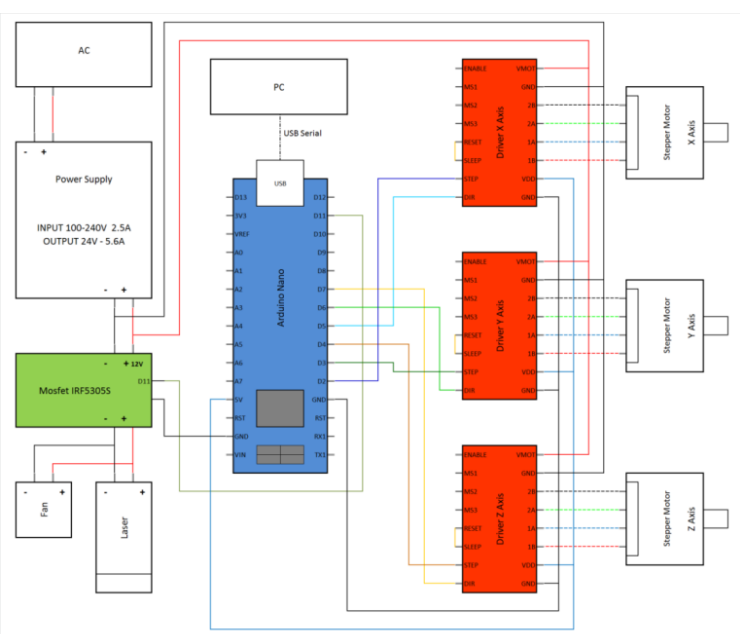

Gambar 3. Skema sistem kontrol.

Perancangan sistem kontrol aktuator pada mesin gravir laser menggunakan motor stepper sebagai penggerak terhadap sumbu $\mathrm{X}, \mathrm{Y}$ dan $\mathrm{Z}$. dengan menggunakan driver stepper type A4988 dengan skema rankaian seperti pada Gambar 4.

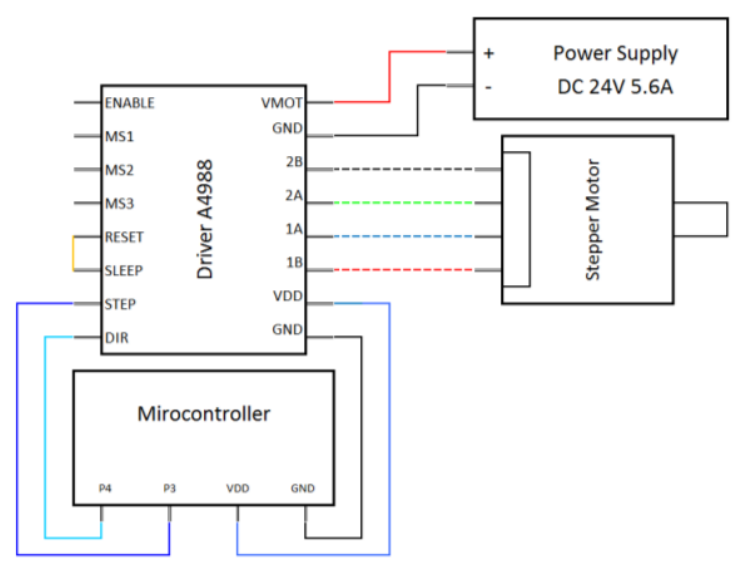

Gambar 4. SIstem kontrol aktuator.

Untuk menggerakan motor stepper, kita harus memberikan pulsa $5 \mathrm{~V}$ tegangan pada 4 pin motor stepper dengan pola urutan tertentu. Satu urutan tertentu tersebut akan menggerakan satu step (1.8 O). Memutar satu putaran penuh motor stepper (360 O), dilakukan dengan mengulang 1 step tersebut sebanyak 200 kali dari perhitungan berikut $(360 \mathrm{O} / 1.80 \mathrm{O}=200$ step), untuk menggerakan satu step maka 4 pin itu harus dikasih pulsa dengan empat langkah seperti pada Tabel 4.

Tabel 4. Urutan langkah.

\begin{tabular}{ccccc}
\hline Step & Pin 1 & Pin $\mathbf{2}$ & Pin $\mathbf{3}$ & Pin $\mathbf{4}$ \\
\hline$\# 1$ & LOW & LOW & HIGH & HIGH \\
$\# 2$ & HIGH & LOW & LOW & HIGH \\
$\# 3$ & HIGH & HIGH & LOW & LOW \\
$\# 4$ & LOW & HIGH & HIGH & LOW \\
\hline
\end{tabular}

Perancangan sistem kontrol gravir laser menggunakan mosfet IRF5305S sebagai saklar on/off dengan dengan input PWM pada Gate maka akan mengontrol tegangan yang lewat melalui Source ke Drain. Besar kecil nya tegangan yang di lalui Source dan Drain ini ditentukan besar kecil nya nilai PWM yang di input di Gate dari controller. Skema rangkaian seperti pada Gambar 5.

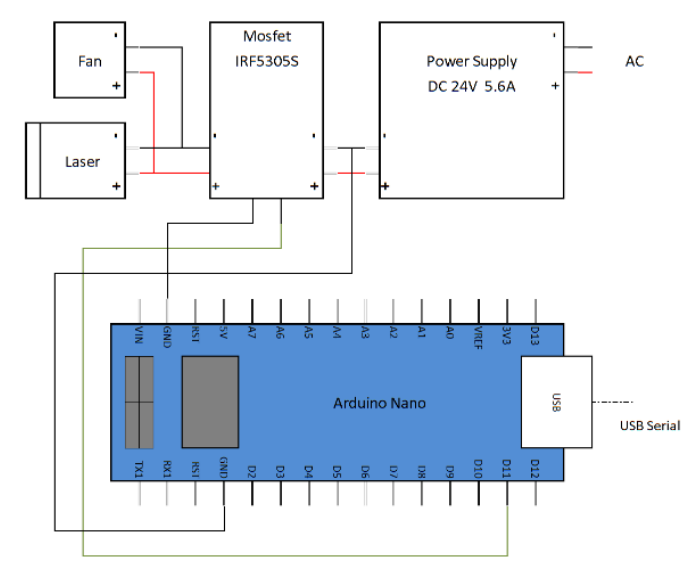

Gambar 5. Sistem kontrol laser.

Dalam rancang bangun mesin gravir laser dengan mikrokontroler arduino telah mengasilkan prototipe mesin gravir laser seperti pada Gambar 6.

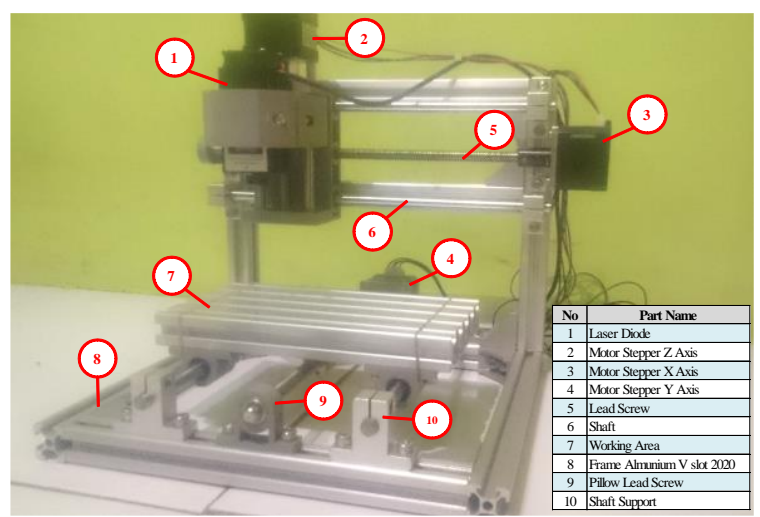

Gambar 6. Prototype mesin gravir laser.

Spesifikasi mesin gravir laser dalam kajian rancang bangun mesin gravir laser menggunakan mikrokontroler arduino nano.

Tabel 5. Spesifikasi mesin gravir laser.

\begin{tabular}{ll}
\hline Control software & Laser GRBL \\
Controller & Arduino Nano \\
Frame & Alumunium V slot 2020 \\
Actuator & Motor Stepper 0.25 N.m 1.3 A \\
Power supply & DC 24V 5A \\
Laser & $2500 \mathrm{~mW} 12 \mathrm{~V}$ \\
Work area & $10 \mathrm{~mm} \times 180 \mathrm{~mm}$ \\
Dimension & $220 \mathrm{~mm} \times 240 \mathrm{~mm} \times 260 \mathrm{~mm}$ \\
\hline
\end{tabular}

Uji kestabilan kontrol sistem berbasis arduino nano dilakukan dengan analisis hasil dari trial and error pada proses gravir laser terhadap hasil akhir dan lebar garis gravir pada material. Dengan metode pengujian 
yang dilakukan yakni, pengujian sistem kontrol dan fungsi aktuator terhadap gerak linier sumbu $X$ dan sumbu Y dengan proses gravir laser membuat bentuk lingkaran, persegi dan gambar. Kemudian dilakukan pengujian sistem kontrol dan fungsi laser dengan uji proses gravir garis dan gambar. Pengujian kinerja sistem kontrol mesin gravir laser dengan menggunakan parameter jarak laser, daya laser, kecepatan gerak laser head. Pengujian kepresisian mesin gravir laser dengan membandingkan dimensi hasil dari proses gravir laser dengan perintah atau masukan pada sistem kontrol. Menganalisis data dari hasil pengujian yang dilakukan.

\section{Hasil dan Pembahasan}

Pada bagian ini menjelaskan mengenai proses pengujian yang selanjutnya dilakukan analisis untuk memperoleh data yang dibutuhkan sesuai dengan hasil yang diharapkan agar mesin gravir laser ini bisa digunakan dengan baik.

\section{Pengujian Sistem Kontrol}

Pengujian sistem kontrol pada mesin gravir laser dilakukan dengan beberapa metode pengujian mengacu kepada sistem kontrol dan fungsi dari aktuator serta laser yang digunakan. Pengujian sistem kontrol dan fungsi aktuator dengan cara membuat garis vector berupa persegi, lingkaran dan gambar dengan hasil yang dapat dilihat pada Tabel 6.

Tabel 6. Hasil pengujian sistem kontrol dan fungsi aktuator.

\begin{tabular}{|c|c|c|c|c|c|}
\hline No & $\begin{array}{c}\text { Kecepata } \\
\text { ngerak } \\
\mathbf{m m} / \mathbf{m i n}\end{array}$ & $\begin{array}{c}\text { Daya } \\
\text { Laser }\end{array}$ & $\begin{array}{c}\text { Jarak } \\
\text { Head } \\
\text { Laser } \\
(\mathbf{m m})\end{array}$ & Input & Hasil \\
\hline 1 & 200 & 255 & 75 & Persegi & \\
\hline 2 & 200 & 255 & 75 & Lingkaran & \\
\hline 3 & 200 & 255 & 75 & Gambar & \\
\hline
\end{tabular}

Pengujian sistem kontrol dan fungsi laser dengan cara membuat garis, persegi dan gambar dengan hasil yang dapat dilihat pada Tabel 7 .
Tabel 7. Pengujian sistem kontrol dan fungsi laser.

\begin{tabular}{|c|c|c|c|c|c|}
\hline No & $\begin{array}{c}\text { Kecepatan } \\
\text { gerak } \\
\text { mm/min }\end{array}$ & $\begin{array}{c}\text { Daya } \\
\text { Laser }\end{array}$ & $\begin{array}{c}\text { Jarak } \\
\text { Head } \\
\text { Laser } \\
\text { (mm) }\end{array}$ & Input & Hasil \\
\hline 1 & 200 & 255 & 75 & Garis & \\
\hline 2 & 200 & 255 & 75 & Persegi & \\
\hline 3 & & & & & \\
\hline & & & & & \\
\hline & & & & & \\
& & & & & \\
\hline
\end{tabular}

\section{Pengujian Mesin Gravir Laser}

Pengujian kinerja dari mesin gravir laser dilakukan dengan parameter jarak laser head, daya laser dan kecepatan gerak laser. Untuk menentukan nilai dari parameter yang digunakan pada proses gravir laser. Pengujian sistem kontrol mesin gravir laser menggunakan parameter jarak laser head terhadap benda kerja agar menghasilkan garis gravir yang baik, dengan menentukan nilai parameter jarak ideal laser head terhadap benda kerja yang akan di proses gravir. Pengujian dilakukan dengan variasi jarak laser yang berbeda, seperti pada Tabel 8 .

Tabel 8. Pengujian dengan metode jarak laser.

\begin{tabular}{|c|c|c|c|c|l|}
\hline No & $\begin{array}{c}\text { Kecepatan } \\
\text { gerak } \\
\mathbf{m m} / \mathbf{m i n}\end{array}$ & $\begin{array}{c}\text { (S-Max) } \\
\text { Daya laser }\end{array}$ & $\begin{array}{c}\text { Jarak } \\
\text { Head } \\
\text { Laser } \\
\text { (mm) }\end{array}$ & Hasil & Keterangan \\
\hline 1 & 200 & 255 & $\mathbf{7 5}$ & & $\begin{array}{l}\text { Garis yang } \\
\text { dihasikan } \\
\text { lebih stabil }\end{array}$ \\
\hline 2 & 200 & 255 & $\mathbf{6 0}$ & & $\begin{array}{l}\text { Garis yang } \\
\text { dihasilkan } \\
\text { terlalu tebal }\end{array}$ \\
\hline 3 & 200 & 255 & $\mathbf{4 5}$ & & \\
\hline & & & & & \\
\hline
\end{tabular}


Pengujian sistem kontrol mesin gravir laser dengan menggunakan parameter daya laser yang digunakan dalam proses gravir. Menentukan nilai parameter daya laser ideal agar menghasilkan gravir yang baik, dilakukan pengujian dengan menggunakan variasi daya laser yang berbeda seperti pada Tabel 9 .

Tabel 9. Pengujian dengan metode daya laser.

\begin{tabular}{|c|c|c|c|c|c|}
\hline No & $\begin{array}{c}\text { Kecepatan } \\
\text { gerak } \\
\mathrm{mm} / \mathrm{min}\end{array}$ & $\begin{array}{l}\text { (S-Max) } \\
\text { Daya } \\
\text { laser }\end{array}$ & $\begin{array}{l}\text { Jarak } \\
\text { Head } \\
\text { Laser } \\
\text { (mm) }\end{array}$ & Hasil & Keterangan \\
\hline 1 & 200 & 105 & 75 & & $\begin{array}{l}\text { Garis yang } \\
\text { dihasilkan } \\
\text { kurang tebal }\end{array}$ \\
\hline 2 & 200 & 156 & 75 & & $\begin{array}{l}\text { Garis yang } \\
\text { dihasilkan } \\
\text { cukup tebal dan } \\
\text { jelas }\end{array}$ \\
\hline 3 & 200 & 205 & 75 & & $\begin{array}{l}\text { Garis yang } \\
\text { dihasilkan tebal }\end{array}$ \\
\hline 4 & 200 & 255 & 75 & & $\begin{array}{l}\text { Garis yang } \\
\text { dihasilkan } \\
\text { terlalu tebal }\end{array}$ \\
\hline
\end{tabular}

Pengujian sistem kontrol mesin gravir laser dengan parameter kecepatan gerak laser dalam proses gravir. Menentukan nilai parameter kecepatan gerak laser dengan pengujian variasi kecepatan gerak laser yang berbeda, dengan hasil seperti pada Tabel 10.
Tabel 10. Pengujian dengan metode kecepatan gerak laser.

\begin{tabular}{|c|c|c|c|c|c|}
\hline No & $\begin{array}{c}\text { Kecepatan } \\
\text { gerak } \\
\text { mm/min }\end{array}$ & $\begin{array}{c}\text { (S-Max) } \\
\text { Daya laser }\end{array}$ & $\begin{array}{l}\text { Jarak } \\
\text { Head } \\
\text { Laser } \\
\text { (mm) }\end{array}$ & Hasil & Keterangan \\
\hline 1 & 100 & 155 & 75 & & $\begin{array}{l}\text { Garis yang } \\
\text { dihasilkan terlalu } \\
\text { tebal }\end{array}$ \\
\hline 2 & 200 & 155 & 75 & & $\begin{array}{l}\text { Garis yang } \\
\text { dihasilkan } \\
\text { nampak jelas }\end{array}$ \\
\hline 3 & 300 & 155 & 75 & & $\begin{array}{l}\text { Garis yang } \\
\text { dihasilkan tipis }\end{array}$ \\
\hline 4 & 400 & 155 & 75 & & $\begin{array}{l}\text { Garis yang } \\
\text { dihasilkan putus- } \\
\text { putus }\end{array}$ \\
\hline & & & & & \\
\hline
\end{tabular}

Pengujian akurasi sistem kontrol mesin gravir laser dengan menganalisis hasil dari proses gravir dan membandingkan ukuran aktual dengan masukan pada sistem kontrol, yang dapat dilihat pada Tabel 11.

Tabel 11. Pengujian dengan kecepatan gerak laser.

\begin{tabular}{|c|c|c|c|c|c|c|}
\hline No & $\begin{array}{c}\text { Kecepatan } \\
\text { mm/min }\end{array}$ & $\begin{array}{c}\text { (S-Max) } \\
\text { Daya } \\
\text { laser }\end{array}$ & $\begin{array}{l}\text { Jarak } \\
\text { Head } \\
\text { Laser } \\
(\mathrm{mm})\end{array}$ & Input & Hasil & Keterangan \\
\hline 1 & 200 & 255 & 75 & $\begin{array}{c}\begin{array}{c}\text { Persegi } \\
\text { ukuran } \\
30 \mathrm{~mm} \times 30 \mathrm{~mm}\end{array}\end{array}$ & & $\begin{array}{c}\text { Hasil ukur } \\
30 \mathrm{~mm} \times 30 \mathrm{~mm} \\
\text { (dari center line) } \\
\text { Lebar garis } \\
0.6 \mathrm{~mm}\end{array}$ \\
\hline 2 & 200 & 255 & 75 & $\begin{array}{c}\text { Persegi } \\
\text { ukuran } \\
20 \mathrm{~mm} \times 20 \mathrm{~mm}\end{array}$ & & $\begin{array}{c}\text { Hasil ukur } \\
20 \mathrm{~mm} \times 20 \mathrm{~mm} \\
\text { (dari center line) } \\
\text { Lebar garis } \\
0.6 \mathrm{~mm}\end{array}$ \\
\hline 3 & 200 & 255 & 75 & $\begin{array}{c}\text { Persegi } \\
\begin{array}{c}\text { ukuran } \\
10 \mathrm{~mm} \times 10 \mathrm{~mm}\end{array}\end{array}$ & & $\begin{array}{c}\text { Hasil ukur } \\
10 \mathrm{~mm} \times 10 \mathrm{~mm} \\
\text { (dari center line) } \\
\text { Lebar garis } \\
0.6 \mathrm{~mm}\end{array}$ \\
\hline 4 & 200 & 255 & 75 & $\begin{array}{c}\text { Lingkaran } \\
\text { ukuran } \\
\text { Diameter } \\
30 \mathrm{~mm}\end{array}$ & & $\begin{array}{c}\text { Hasil ukur } \\
\text { Diameter } 30 \mathrm{~mm} \\
\text { (dari center line) } \\
\text { Lebar garis } \\
0.6 \mathrm{~mm}\end{array}$ \\
\hline 5 & 200 & 255 & 75 & $\begin{array}{l}\text { Lingkaran } \\
\text { ukuran } \\
\text { Diameter } \\
20 \mathrm{~mm}\end{array}$ & & $\begin{array}{c}\text { Hasil ukur } \\
\text { Diameter } 30 \mathrm{~mm} \\
\text { (dari center line) } \\
\text { Lebar garis } \\
0.6 \mathrm{~mm}\end{array}$ \\
\hline 6 & 200 & 255 & 75 & $\begin{array}{l}\text { Lingkaran } \\
\text { ukuran } \\
\text { Diameter } \\
10 \mathrm{~mm}\end{array}$ & & $\begin{array}{c}\text { Hasil ukur } \\
\text { Diameter } 30 \mathrm{~mm} \\
\text { (dari center line) } \\
\text { Lebar garis } \\
0.6 \mathrm{~mm}\end{array}$ \\
\hline
\end{tabular}


Hasil data pengujian mesin gravir laser ini diperoleh dari beberapa tahap pengujian terhadap parameter yang sudah ditentukan seperti jarak laser, daya laser dan kecepatan gerak laser, guna mencari nilai parameter yang tepat untuk suatu material yang akan diproses gravir menggunakan laser. Sehingga didapatkan bahwa jarak ideal $75 \mathrm{~mm}$, nilai ideal $S$ Max pada controller Laser GRBL adalah 255. Nilai ideal Border speed pada controller Laser GRBL adalah 200. Hasil analisis data pengujian kinerja mesin gravir laser, sistem kontrol berjalan dengan baik dan akurat, serta didapat nilai parameter yang ideal dijadikan standar.

\section{Kesimpulan}

Perancangan dan pembuatan prototipe mesin gravir laser 2 axis telah dilakukan beberapa langkah dan metode sehingga dapat bekerja dengan baik. Dari hasil pengujian mesin gravir laser dengan menggunakan parameter jarak laser, daya laser dan kecepatan gerak laser, Dapat disimpulkan nilai parameter mesin gravir laser dan dijadikan standar parameter seperti pada Tabel 4.

Tabel 4. Standar parameter mesin gravir laser.

\begin{tabular}{cccc}
\hline Material & $\begin{array}{c}\text { Kecepatan } \\
\text { gerak } \\
(\text { mm.min })\end{array}$ & $\begin{array}{c}\text { S-Max } \\
\text { Daya } \\
\text { laser }\end{array}$ & $\begin{array}{c}\text { Jarak } \\
\text { Head } \\
\text { Laser } \\
(\mathbf{m m})\end{array}$ \\
\hline Karton & 200 & 255 & 75 \\
\hline
\end{tabular}

Untuk menghindari kesalahan dalam pergerakan mesin, telah dilakukan kalibrasi unit antara sistem interface dengan pergerakan mesin, sehingga perintah dengan unit tertentu pada komputer akan dieksekusi tepat oleh mesin gravir laser. Saran yang dapat disampaikan yakni bahwa kalibrasi sebelum proses diperlukan untuk menghindari terjadinya kerusakan akibat error pada sistem kontrol. Menambahkan limit swicth pada sumbu $\mathrm{X}$ dan sumbu $\mathrm{Y}$ untuk meningkatkan sistem keamanan. Untuk standar parameter gravir pada kayu dan akrilik perlu pengujian lebih lanjut. Laser module yang digunakan dapat diganti dengan motor spindle.

\section{Daftar Pustaka}

[1] Ikhlash Syukran Harrizal. 2017. Rancang bangun sistem kontrol mesin cnc miling 3 axis menggunakan close loop systems. Teknik Mesin, Universitas Riau [journal]. Tersedia pada: https:/media.neliti.com/ media/publications/ 184294-ID-rancang-bangun-sistem-kontrolmesin-cnc.pdf., diunduh 2018 Feb 8.

[2] Devri Naldy. 2016 .Perancangan dan Analisis Struktur Mekanik Prototipe Mesin CNC Milling 3-Axis.Fakultas Teknik, Universitas Riau [journal]. Tersedia pada: https://media.neliti.com/media/publications/201 413, diunduh 2018 Feb 8.
[3] Daniel Costa. 2016. Laser engraver with arduino. Tersedia pada: https://www.hackster.io/macinblack/laserengraver-with-arduino-719d14, diakses 2018 Feb 18.

[4] Laser GRBL. 2013. WHAT IS LASERGRBL. Tersedia pada: http://lasergrbl. com/en/ , diunduh 2018 Apr 12.

[5] Osoyoo. 2017 .Arduino NANO +CNC Shield V4.0+A4988 User Manual. Tersedia pada: http://osoyoo.com/2017/04/07/arduino-nanocnc-shield-v4-0a4988/ diakses 2018 Feb 18.

[6] Getburnt. 2013. Arduinogravir laser.Tersedia pada: http://www.instructables. com/id/ArduinoLaser-Engraver/, diakses 2018 Feb 18.

[7] Tiffany Kwan. 2015. Tips for a DIY Laser. Tersedia pada: http://blog. productgraph.io/ tipsfor-a-diy-laser/, diakses 2018 Feb 18.

[8] Sinauarduino. 2016. Mengenal Arduino Software IDE. Tersedia pada: http://www. sinauarduino.com/artikel/mengenal-arduinosoftware-ide/, diakses 2018 Feb 20.

[9] Wikipedia. 2018. Laser diode. Tersedia pada: https://en.wikipedia.org/wiki/ Laser_diode, diakses 2018 Feb 18.

[10] Wikipedia. 2018. Judul.Mosfet. Tersedia pada: https://id.wikipedia.org/wiki /MOSFET, diakses 2018 Mar 16.

[11] CompounentsIOI. 2018. Arduino Nano. Tersedia Pada: https://components101. com /mikrokontrolers/arduino-nano, diakses 2018 Feb 19.

[12] Calincostelcoty. 2016. Diy Arduino Laser Engraver.. Tersedia pada: http://www.instructables.com/id/Diy-ArduinoLaser-Engraver/, diakses 2018 Feb 18.

[13] Daniel Costa. 2016. Laser engraver with arduino. Tersedia pada: https://www. hackster.io/macinblack/laser-engraver-witharduino-719d14, diakses 2018 Feb 18.

[14] Mikro1311860. 2015. Kendali motor stepper dengan arduino uno. Tersedia pada:https://mikro1311860.wordpress.com/201 5/11/09/kendali-motor-stepper-dengan-arduinouno/, diakses 2018 May 2. 